\title{
Effects of Strategic Human Resource Management Model to Achieve Strategy
}

\author{
Ming-Ming CHEN \\ Business School Hohai University, Nanjing, China 210036 \\ lisa.cmm@foxmail.com
}

Keywords: Strategic human resource management, Strategy implementation, Impact model, Decision making attention.

\begin{abstract}
With the strategic human resource management inherent mechanism analysis, we find that the strategic human resource not only has strategy attributes, manage properties and people of the property, but also has a longitudinal consistency and transverse dependence in each module. Through aggregation to the strategic goal of management and excitation to the management on the process. Strategic human resource management makes the enterprise internal attention together, achieve thereby further through the enterprise internal resource allocation, implementation of the enterprise strategy management method, promotion on enterprise organization ability to achieve strategic objectives.
\end{abstract}

\section{Introduction}

Corporate strategic human resource management is how to play a corresponding impact on the strategy to achieve, has been a topic of great concern to the business community. However in the past, the domestic and foreign research only stay on the correlation mechanism between the two, not in-depth analysis of the impact of the relationship between one another. This paper analyzes the inner mechanism of strategic human resources, combined with the practice of enterprise management, puts forward the interaction of principle and process of strategy implementation to the strategic human resources management, points out the strategic human resources through the enterprise decision-making attention to achieve a corporate strategy. Finally, put forward the influence of strategic human resource management on strategy implementation.

\section{The analysis of strategic human resources management mechanism}

\section{The analysis of strategic human resources management common, difference and causal logic}

Strategic Human Resource Management modules have a strategic property, management property and people of this property. At the same time, the differences in strategic human resource management modules are also very obvious, that they have goal-oriented differences, continuity differences and focus difference.

Since the 1980s, human resource management is the key to the success of corporate strategy, its core functions are involved in strategic decision-making, attention to the consistency of employee goals with organizational goals. Strategic human resource management is be matching the strategic in the longitudinal direction, and be matching the management practice in the lateral, it has the interdependency in its internal.

\section{The relationship between strategic human resource management,company goals, strategy and} the external environment.

The basic idea of strategic human resource management is the starting point of the "investment concept"[1], but this view in many enterprises is not adopted, the main reason is due to fear of wasting money and effort invested that caused by the staff loss.

Strategic human resources stressed, to implement corporate strategy is closely linked by the enterprise strategy and human resources, emphasized the consistency of human resource 
management and enterprise strategy, human resource management practice is to enhance the enterprise strategy as the goal, in this condition, to influence the business performance through the practice of human resource management, to build the core competitiveness of enterprises, from the existing stock of human resources training the workforce with the core competitiveness, creating a rigorous and effective management system, cultivate a positive corporate culture.

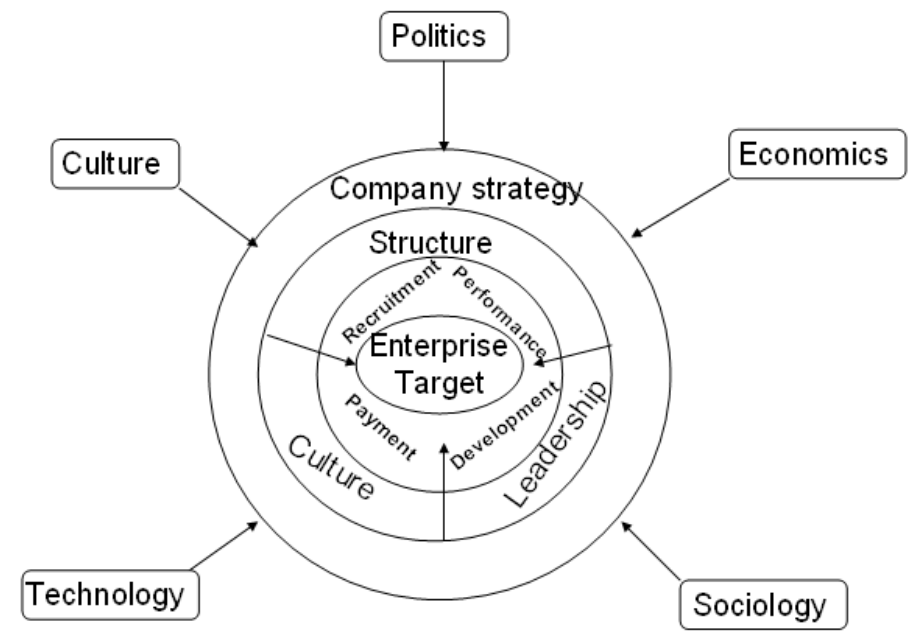

Fig. 1 The model of the relationship between strategic human resource management, company goals, strategy and the external environment

The above model is based on four aspects to the division, the whole is a bicycle wheel shape, axis is the enterprise objective, the outermost layer is the external environment of enterprise open; The second layer is the company strategy, company strategy determines the target of the enterprise, also determines the level of enterprises to participate in market competition mode, similar to the wheel type; The third level is the key part of corporate strategy, to support the implementation of the strategy, similar to tire tube such as culture, structure and leadership; The fourth level is the specific human resource strategy, but also can be said to be the traditional focus on human resources management, which is reflected the enterprise internal human resources system level. This level is similar to the wheel spokes, both to support the company strategy, but also to cooperate with each other, no matter which spokes fracture, will affect the wheels, and will entangle axis, causes the enterprise objectives not be achieved or even cause damage. Strategic human resource management is to play a role in these four levels to realize the goal of enterprise.

\section{The intermediary role of enterprise strategic decision of attention}

\section{Decision attention definition and connotation}

The attention concept is the first concept in the field of cognitive science; first introduced the concept of attention from cognitive science management is management guru Simon. Simon thinks, "management is decision-making", and all enterprises to make decision will be based on how to allocate their attention. [2] Another management guru Madge, also based on "effective rational", and further raised the importance of "attention allocation" in the organization running. Madge believed that "the attention is a scarce resource", the decision is not only a choice, decision-making is the key to search, and decided to search for the way of attention. In the enterprise through management, control, adjustment of attention, it will be cause different effect to the enterprise decision. [3] Ocasio further proposed the enterprise attention based view, and made the research from the perspective of individual decision-making into enterprise whole decision system. He think: attention allocation is the management process that the decision makers will take their time and experience for attention, encoding, and focusing on the organizational problems and solutions. [4] 
Enterprise strategic attention is not only the process of strategy formulation; it is also concerned about the process of the implementation of the strategy. In strategy formulation and implementation process as a strategic human body have two defects which cannot be avoided: First, people cannot focus their attention on several objectives at the same time; Second, people cannot focus their attention on strategic the entire decision-making process. This means that both for the strategy-maker, or the strategy-implementer, their attention is limited. This will surely lead to some defects may be ignored; some errors may be ignored in strategy formulation and implementation process. [5] So unless strategy formulation and strategy implementers can focus on strategic policy decision, otherwise even the best strategy and organizational structure cannot play its due role. In the process of strategic decision making, attention resource is a scarce resource; the configuration of attention will affect the search and selection of information, thus affecting the results of decisions.

\section{Strategic human resource management will result in corporate decision-making gathering attention}

The important value of Strategic human resource management to strategy implementation comes from the strategic human resource management with a consistent goal-oriented, strategic human resources always focused on achieving strategic objectives, corporate strategic human resource planning in order to achieve the strategic goal, the company's strategic human resource acquisition, configuration, organizational structure, training are all developed under the strategic goal of enterprise, corporate strategic human resource incentives, employee relations management are achieve around these strategic objectives of the strategy.

Strategic human resource management is also important source of value realization of enterprise strategy in the enterprise resource oriented role, reconfigure it will cause all human, material and financial resources, resources and other resources of the enterprise to realize the enterprise strategic target direction better. In addition, strategic human resource management will also be incentives for business activities play a role in the process of systems, processes and policies.

Through the management of the strategic objectives of aggregation, re-configure the resources and incentives to strengthen the management process, strategic human resource management so that enterprises gathered attention from top to bottom, the companies have to boot from ideology to full working practices to the same goal - the effective realization of the strategic objectives of the enterprise.

\section{Decisions attention to ensure the realization of corporate strategy}

At the same time, in today's information era, only through the effective decision concerned, to ensure the consistent implementation of enterprise strategy, and ultimately to achieve enterprise strategic goals.

Meanwhile, decision attention will also allow enterprises to adjust its strategic management approach in the management process to ensure that the strategic goals of the foundation, adjust organizational structure and internal management support systems, the configuration of enterprise resources, by organizing a variety of communication channels information exchange to ensure that companies have an effective incentive and a support force of culture, so that the strong organizational skills upgrading.

\section{Analysis of strategic human resources's Impact model of strategic implementation}

\section{The impact of the mechanism of strategic human resource to strategies decision of attention}

Research on strategic human resource management mode of operation, from strategic human resource planning, strategic human resource obtaining configuration, strategic human resource training and strategic human resources incentive aspects reveals its is decision attention gathering and decision attention management effect in the strategic management process.

Decision-making concentration. Strategic human resource acquisition and allocation under the guidance of strategic human resource planning, match with the enterprise strategy of talent, through 
internal staff promotion, transfer, eliminated, effective flow of personnel within the organization to achieve corporate strategic decision-making attention aggregation. Strategic human resource training is to achieve a spread within the enterprise to achieve maximum organizational strategy, ensure that create a conducive to the realization of enterprise strategy organization atmosphere and enterprise culture, to improve enterprise staff's work enthusiasm and work ability, and to achieve the focus of enterprise strategic management decision aggregation.

Decision-making management attention. According to the theory of attention basic concept: Decision attention have continuity, transferability and selectivity characteristics. [6] Continuous attention means that managers will attention management in accordance with the established order; transferable attention means that decision attention will shift with the situational factors; selective attention means that decision will be the focus of allocation oodles of stimulus related project. Therefore, in analyzing the attention of decision-making, attention management is one of the very important module.

Through Strategic objectives gather of business management, re-allocation of resources and strengthen incentives of management process, strategic Human Resource Management allows companies to effectively manage the attention of management decisions, allows companies of all employees to work around the same goal -- the strategic goal of the enterprise, from ideology to practice, ultimately achieved the focus strategy decision attention in enterprise management.

\section{The impact of strategies decision of attention to Strategy implementation}

Corporate strategic decision-making has a very important influence attention in the strategic significance of the implementation process, it is not only concerned about the process of strategy formulation, but also concerned about the process of strategy implementation. Strategic management decision-making process resulted in limited attention in the strategic management focus on strategic objectives and resource requirements-oriented requirements, so attention is an inherent requirement of the strategic decision-making strategy implementation. Influence strategic decisions attention is always through the internal allocation of resources for the implementation of corporate strategic management approach, to enhance the ability of the organization to achieve.

The allocation of resources. The enterprise strategy to the floor, depending on the efficient allocation of resources on the course of business operations ,from the rational allocation of organizational structure and the rational allocation of policy resources to other related resources, by ensuring that the strategy oriented enterprise resources, and protecting that effective use of supporting enterprises of various resources ,to ensure that the enterprise strategy can really fall, but also to ensure the realization of enterprise strategy.

Strategic management method. Enterprise strategy, no doubt affected by the corporate management constraints . Business management method, its essence is a form of enterprise decision attention, through effective incentive means, strong support of culture, internal management supporting system and effective methods of leadership, deeply affect the enterprise strategy implementation. This powerful influence can be from an unseen hand, it may not be a kind of administrative coercive means, but it plays a more effective role than administrative means of influence.

Organizational capacity building. The realization of enterprise strategy is also affected by the organizational capability. Organizational capacity building is dependent enterprises continue to shape the unique capabilities and build a strong business management team. In the implementation of the strategy process, enterprises always around the development and promotion of the core ability and special ability, strong organization ability is the strong support to enterprise strategy. And a capable and efficient management team, can make the best decision in the process of the implementation of the strategy, and can use the specific skills to ensure the realization of enterprise strategy in making least mistakes, all employees will gather together to promote the whole enterprise member of the strategic decision to focus attention on the company's strategy, and ultimately ensure the realization of the strategic objectives of the enterprise. 


\section{Constructing the Influence model of strategic human resource management and strategy implementation}

Through the above analysis, we can clearly confirm that attention in the strategic decision-making is the role of the media to the strategic human resources management and the strategy implementation, to further the mutual influence between the strategic human resource management and the strategy implementation can be regarded as a relatively independent integration model to study. Around the interacting elements, the target focusing, configuration guide and process incentive, which in the strategic decision of attention, promote the effect of strategic human resource management to the strategic implementation.

Taking these elaborate, figure 2 shows the influence model between the strategic human resource management, the strategic implementation and the strategic decision of attention.

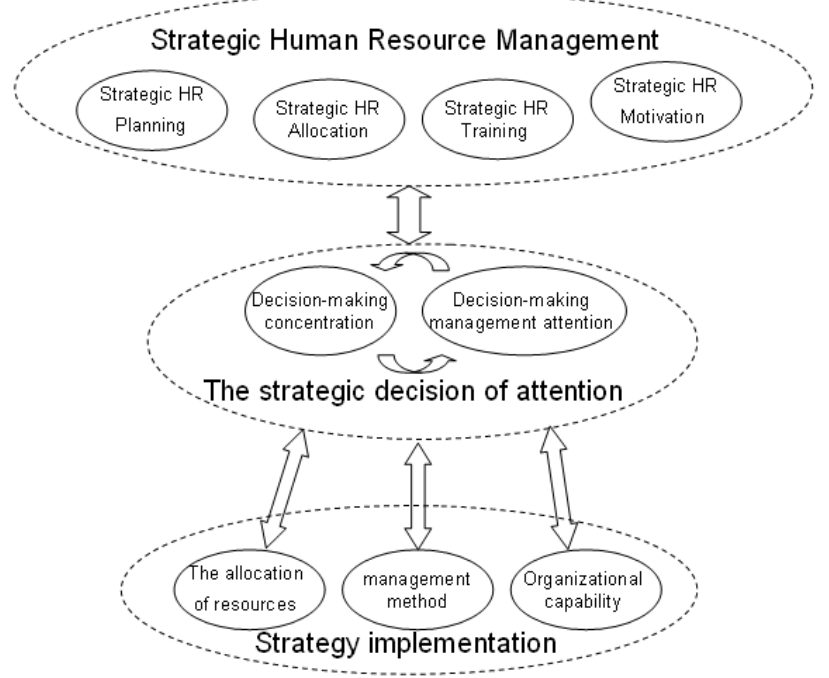

Fig. 2 The influence model between the strategic human resource management, the strategic implementation and the strategic decision of attention

\section{Conclusion}

Strategic human resource management must be highly consistent with the strategic goals in key decisions, keep making attention selectively focused and targeted transfers. On one hand, through effective focus on key decisions, to ensure the effective implementation of strategic objectives; on the other hand, through the ongoing management of key decisions to ensure the regulatory follow-up and process excitation of the strategic objectives of improving, and ultimately ensure the effective fulfillment of enterprise strategy.

\section{References}

[1] Li ying, “A review of western strategic human resource management,” Dong Yue Tribune, 2005, pp. 175-177.

[2] Simon, Administrative behavior:A study of decision-making processes in administrative organizations[M], New York:Free Press, 1947.

[3] March,A primer on decision making:How decisions happen[M], New York:Free Press, 1994.

[4] Ocasio,Towards an attention-based view of the firm[J], Strategic Management Journal, 1997,pp:187-206. 
[5] Davenport,T H,and Beck,J C. Getting the attention you need[J],Harvard Business Review,2000,pp:118-126.

[6] Wu Jianzu, and Wang Xinran, "Based on analysis of the present situation of foreign attention view and future prospects”, Foreign Economics \& Management, 2009, pp.58-65. 